\title{
KONSEP KHIYAR PADA JUAL BELI PRE ORDER ONLINE SHOP DALAM PERSPEKTIF HUKUM ISLAM
}

\author{
Dafiqa Hasanah \\ Universitas Ibn Khaldun Bogor, Indonesia \\ e-mail: fiqahasanah@gmail.com \\ Mulyadi Kosim \\ Universitas Ibn Khaldun Bogor, Indonesia \\ e-mail: kosim@uika-bogor.ac.id \\ Suyud Arif \\ Universitas Ibn Khaldun Bogor, Indonesia \\ e-mail: suyud@uika-bogor.ac.id
}

\begin{abstract}
:
This study aims to determine the practice of online pricing in the online store instagram Tiw's.id. the method used is descriptive qualitative with field research type. Khiyar right is the choise to cancel or establish a contract for both the seller and the buyer. The right of khiyar is a proof of the perfection of Islam in a business between two people who intend to create mutually acceptable transactions and avoid fraud. On a free purchase or purchase directly in general, you can check the items you want to buy like the disable items or the quality of the items, but its diffrent by buying online, the limited internet makes the khiyar right not noticed by both the seller and the buyer.
\end{abstract}

Keywords: khiyar right, online shop, Islamic perspektif.

\section{Pendahuluan}

Jual beli merupakan salah satu aktivitas dalam fiqih muamalah yang paling sering dilakukan oleh manusia sebagai bentuk pemenuhan kebutuhan sehari-hari. Mulai dari jual beli untuk memenuhi kebutuhan sehari-hari seperti bahan makanan sampai jual beli produk elektronik, alat-alat rumah tangga, dan lain-lain.

Jual beli sendiri ialah proses tukar menukar harta, atau suatu (manfaat/jasa) yang halal ditukar dengan hal yang serupa dengannya untuk masa yang tak terbatas, dengan cara-cara yang dibenarkan. ${ }^{1}$ Oleh karena itu jual-beli bukanlah hanya sebatas proses tukar menukar, tetapi juga meliputi harta/barang jual yang halal, juga praktik usaha halal yang tidak hanya berorientasi pada keuntungan semata tapi juga mengedepankan nilai-nilai dan tata cara jual-beli dalam Islam.

Pada keadaan dimana teknologi informasi berkembang sangat pesat, dimana internet kini dapat dengan mudah diakses kapanpun dan dimanapun oleh semua orang. maka hal ini

1 Badri Bin Arifin Muhammad, Sifat Perniagaan Nabi, (Bogor: Darul ilmi, 2008) 23 
Dafiqa Hasanah, dkk: Konsep Khiyar Pada Jual Beli Pre Order Online...

berdampak pada kemudahan untuk mendapatkan berbagai informasi, begitu juga kemudahan dalam praktik jual beli. Jual beli yang dulunya hanya terbatas dengan tatap muka antara penjual dan pembeli dipasar, kini hanya dengan menggunakan internet ditelepon gemgang (handphone) atau laptop seseorang bisa melakukan jual beli, yang kemudian jual beli ini akrab disebut sebagai jual beli online.

Jual beli online merupakan proses jual beli, pertukaran produk, jasa dan informasi melalui internet. ${ }^{2}$ Meskipun pada dasarnya jual beli online tidak jauh berbeda dengan jual beli pada umumnya namun kembali lagi kepada kaidah muamalahbahwa semua transaksi dibolehkan selama tidak ada dalil yang mengharamkannya. Maka dengan demikian transaksi online sebagai bentuk bisnis baru perlu dikaji praktiknya.

Praktik jual beli online tentunya memiliki sisi positif maupun sisi negatif karena mekanisme jual beli online yang sedikit berbeda dengan jual beli secara langsung. Keterbatasan media dalam praktik jual beli online inilah yang tidak sedikit menimbulkan kerugian diantara penjual maupun pembeli.

Oleh karena itu Islam dalam jual beli mensyariatkan adanya hak khiyar. Yaitu hak menentukan pilihan antara melanjutkan akad atau mebatalkannya. Seperti dalam hadits Rasulullah $S A W$ bersabda.

2 Ayu Lestari, Bisnis Online Syariah, (Jakarta: Kompas Gramedia, 2014) 19
"Dari Hakim bin Hizam bahwasannya Rasulullah SAW bersabda: Kedua penjual dan pembeli berada dalam kebaikan selama mereka tidak berpisah satu sama lain. Maka jika keduanya jujur dan saling memberikan keterangan dengan jelas, semoga jual belinya diberkahi. Namun, jika keduanya dusta dan ada yang saling disembunyikan, hilanglah berkah jual beli keduanya."3

Hadits diatas menyebutkan bahwa Rasulullah $S A W$ mensyariatkannya adanya sebuah hak khiyar bagi penjual maupun pembeli. Hak khiyar juga boleh diminta oleh pihak manapun asal tidak melibihi tiga malam, bahkan pendapat Imam Muhammad dan Imam Abu Yusuf menetapkan tiadanya batas waktu tersebut. ${ }^{4}$

Adapun jenis jual beli dengan penyerahan barang dibelakang yaitu akad salam atau dalam jual beli online sering disebut pre order ialah sebuah akad dimana barang akan diproduksi atau dibuat sesuai dengan pesanan yang ada. Oleh sebab itu, adanya hak khiyar saat akan terjadinya akad dapat menghindarkan adanya kerugian diantara kedua belah pihak sebelum mereka sepakat untuk melanjutkan akad.

Maka dengan itu khiyar sebagai hak bagi penjual maupun pembeli haruslah diterapkan dalam setiap transaksi terlebih dalam jual beli online sebagai sebuah bukti

${ }^{3} \mathrm{HR}$ Mutafaq alaihi, dengan lafazh Bukhari yang dinukil dari Maktabah Syamilah v1.0 (7/302, no. 1968)

4 Muhammad sharif chaundry, Fundamental Of Islamic Economis System, (Jakarta 2014) 12 
252 | Dafiqa Hasanah, dkk: Konsep Khiyar Pada Jual Beli Pre Order Online..

telah diikat. ${ }^{9}$ Misalnya, pembeli mengatakan kepada penjual "saya beli barang ini dari anda, tapi saya punya hak untuk mengembalikan barang ini dalam tiga hari". Begitu periode yang disyaratkan berakhir, maka hak untuk membatalkan yang ditimbulkan oleh syarat ini tidak berlaku lagi. Sebagai akibat dari hak ini, maka kontrak yang pada awalnya bersifat mengikat menjadi tidak mengikat. Hak untuk member syarat jual beli ini membolehkan suatu pihak untuk menunda eksekusi kontrak itu.

c. Khiyar Aib

Khiyar Aib adalah suatu hak yang diberikan kepada pembeli dalam kontrak jual beli untuk membatalkan kontrak jika si pembelki menemukan cacat dalam barang yang telah dibelinya sehingga menurunkan nilai barang itu. Hak itu digariskan oleh hukum dan pihak-pihak yang terlibat tidak boleh melanggarnya dalam kontrak.10 Kebaikan dari hak ini adalah pembeli yang menemukan cacat pada barang yang dibeli mempunyai hak untuk mengembalikannya kepada penjual, kecuali dia mengetahui cacat itu sebelum dibelinya. Adapun cacat yang menyebabkan munculnya hak khiyar aib ini, menurut Wahbah Zuhaily adalah setiap transaksi

9 Muhammad tahir mansori, KaidahKaidah Fiqih Keuangan dan Transaksi Bisnis (bogor, ulil albab institute 2009) 91

10 ibid, Kaidah-Kaidah Fiqih... 59-60 yang rusak dari asal fitrahnya sehingga mengurangi nilainya menurut adat yangberlaku, seperti kadaluarsa, rusak, atau berubah warna. ${ }^{11}$

Hal ini didasarkan pada hadits Rasulullah $S A W$ yng berbunyi.

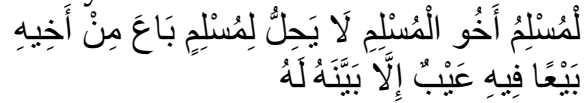

"seorang muslim ialah saudara bagi muslim yang lain. Tidak halal seorang muslim menjual sesuatu kepada saudaranya, kecuali dia menjelaskan barang jualannya tersebut kepada saudaranya itu. (HR. Ibnu Majah Ahmad Al Baihaqi dan alHakim) $^{12}$

d. Khiyar $R u^{\prime} y a h$

Khiyar Ru'yah yakni hak pilihan untuk meneruskan akad atau membatalkannya, setelah barang yang menjadi objek akad dilihat oleh pembeli. Hal ini terjadi dalam kondisi dimana barang yang menjadi objek akad tidak ada dimajelis akad, kalaupun ada hanya contohnya saja, sehingga pembeli tidak tahu apakah barang yang dibelinya itu baik atau tidak. Setelah pembeli melihat langsung kondisi barang yang dibelinya, apabila setuju, ia bisa meneruskan jual belinya dan apabila tidak setuju, ia boleh

11 Wahbah Zuhaily, Al-Fiqh al-Islâm wa 'Adilatuhî) Jilid IV, (Beirut:Dâr AlFikr1984) 569

12 Abu Bakar Ahmad Ibn Al Husain Ibn Aly Al Baihay, As Sunan Al Kubra Wa Fi Dzalihi Al Jauhar An Naqy,hadits no. 11048 (India, Malis Dairah Al Maarif An Nidzamiyyah al kainah, 1344H) 
mengembalikannya kepada penjual, dan jual beli dibatalkan, sedangkan harga dikembalikan seluruhnya kepada pembeli. ${ }^{13}$

Hal ini berdasarkan pada sabda Rasulullah SAW

من اشترى شيئا لم يراه فهو بالخيار اذاراه "siapa yang membeli sesuatu yang belum ia lihat, maka ia berhak khiyar apabila telah melihat barang itu" (HR. adDharqutni dan Abu Hurairah) 14

Akad seperti ini boleh terjadi disebabkan objek yang akan dibeli tidak ada ditempat berlangsungnya akad.

\section{Pengertian Jual Beli}

Jual beli dalam kaidah ushul fiqih disebut dengan al bai' yang berarti menjual, mengganti dan menukar sesuatu dengan sesuatu yang lain. Lafal al bai' dalam bahasa Arab terkadang digunakan untuk pengertian lawannya yakni kata asysyira' (beli). Dengan demikian, kata al bai' bukan hanya berarti jual tetapi sekaligus juga berarti beli. ${ }^{15}$

Dalam kamus besar bahasa Indonesia (KBBI), jual beli ialah perjanjian yang saling mengikat antara penjual yakni orang yang menyerahkan barang dan pembeli sebagai pihak yang membayar barang yang dijual. ${ }^{16}$ Sedangkan jual

${ }^{13}$ AhmadWardiMuslich,

Muamalat. (Jakarta:Amzah) 236

14 Muhammad Dhiya Ar Rahman Al A'Dzhamy, Al Minnah Al Kubra Syarh Wa Takhrij As Sunan Al Shugra, hadits no. 1835 (Riyadh, maktabah ar rusyd 2001M)

15 Nasrun haroen, Fiqih Muamalah, (Jakarta: gaya media pratama, 2007)111

16 KBBI Online

https://kbbi.web.id/jual\%20beli beli dalam Islam lah proses tukar menukar harta, atau suatu (manfaat/jasa) yang halal ditukar dengan hal yang serupa dengannya untuk masa yang tak terbatas, dengan cara-cara yang dibenarkan. ${ }^{17}$

Jual beli atau al bai' sendiri ialah salah satu usaha untuk mendapatkan karunia Allah didunia ini, usaha yang merupakan bagian dari ibadah yang dapat membawa rahmat dan ampunan Allah. Sebagaimana sabda Rasulullah $S A W$

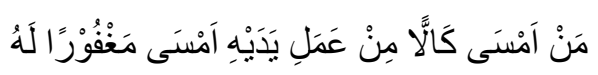

"Barangsiapa yang di waktu sore merasa capek (lelah) lantaran pekerjaan kedua tangannya (mencari nafkah) maka di saat itu diampuni dosa baginya." (HR. Thabrani) ${ }^{18}$

\section{Bentuk-Bentuk Jual Beli}

a. Jual Beli Salam (Pesanan)

Jual beli salam atau pesanan ialah jual beli dimana barang yang dibeli terlebih dahulu dipesan dengan menyebutkan ciri-cirinya kemudian dibayar diawal dan barang yang dipesan diantar kemudian setelah siap dan terpenuhi syarat-syarat yang telah disepakati diawal pada saat pemesanan. ${ }^{19}$

\footnotetext{
${ }^{17}$ Badri bin arifin Muhammad, sifat perniagaan nabi, (Bogor: Darul ilmi, 2008) 23

$18 \mathrm{Abu} \mathrm{Al}$ Qasim Sulaiman Ibn Ahmad at Thabrani, Al Mu'jam Al Ausath, hadist no.7520 (Daar al haramain: Al Qahirah 1415H)

19 Ibdalsyah Hendri tanjung, fiqih muamalah, bogor:azam dunya bogor 2014 h. 64
} 
Dafiqa Hasanah, dkk: Konsep Khiyar Pada Jual Beli Pre Order Online...

Jadi jual beli salam adalah penjualan dimana pembayaran dimuka dilakukan kepada penjual untuk penyediaan barang dikemudian hari. Salam merupakan kontrak yang umum ditemukan sebelum periode Rasulullah $S A W$, tentunya dengan suatu struktrur yang berbeda. Ketika Rasulullah SAW hijrah ke Madinah, kaum Anshar membawa bentuk jual beli ini kepada Rasul untuk menanyakan hukumnya. Rasulullah SAW memberi istilahnya salam dan membolehkan para sahabat melakukannya dengan beberapa syarat. ${ }^{20}$

b. Jual Beli Murobahah

Jual beli murobahah adalah jual beli barang dengan harga asal lalu ditambahkan dengan keuntungan setelah ada kesepakatan antara sipenjual dengan pembeli. Jual beli murobahah ini dibolehkan karena ada unsur tolongmenolong didalamnya. ${ }^{21}$

Syarat-syarat murabahah ialah penjual harus menginformasikan harga asal, akad jual beli yang pertama harus sah, tidak ada unsur riba, kalau ada kecurangan dan cacat pada barang harus disampaikan, harus jelas sistem pembayarannya dan sampai waktu pelunasannya.

c. Istisna'

20 Muhammad tahir mansori, KaidahKaidah Fiqih Keuangan dan Transaksi Bisnis, (bogor: ulil albab institute, 2009) 87-88

${ }^{21}$ Ibid, fiqih muamalah... 66
Istisna ialah suatu kontrak jual beli dimana seorang produsen setuju untuk memproduksi suatu produk tertentu dengan karateristik tertentu yang disepakati sebelumnya. Dengan istisna, seseorang dapat menghubungi seorang pembuat sepatu dengan harga tertentu. ${ }^{22}$

Sama seperti salam, istisna juga merupakan jual beli barang yang tidak ada keberadaannya. Namun dalam istisna pembayaran harga tidak begitu perlu, persoalan ketidakpastian harga atau fluktuasi harga tidak relevan dalam kasus istisna sebab itu adalah komoditas pesanan dan pasar tidak memiliki peran untuk menentukan harganya.

Praktik istisna terjadi saat Rasullah $S A W$ meminta dibuatkan sebuah cincin yang memiliki spesifikasi tertentu. Setelah itu, pembuatannya mengerjakan cincin tersebut sesuai dengan spesifikasi tertentu yang telah ditentukan oleh Rasullah SAW. Kemudian Rasullah $S A W$ mengambilnya dan memakainya dijari kelingking beliau. Ini menunjukkan disyariatkannya akad jual beli istisna. ${ }^{23}$

\section{Jual Beli Online}

Perdagangan elektronik adalah penyebaran, pembelian, penjualan, pemasaranbarang dan jasa melalui sistem elektronik seperti

22 Muhammad tahir mansori, KaidahKaidah Fiqih Keuangan dan Transaksi Bisnis, (bogor: ulil albab institute, 2009) 89

23 Syaikh Ziyad Ghazal, buku pintar bisnis syar'I, (bogor, al azhar press 2011) 128129 
internet atau televisi, www, atau jaringan komputer lainnya. Ecommerce dapat melibatkan transfer dana elektronik, pertukaran data elektronik, sistem manajemen inventori otomatis, dan sistem pengumpulan data otomatis. ${ }^{24}$

\section{Pre Order}

Pre order adalah barang pesanan yang belum dibuatkan. Preorder memungkinkan konsumen untuk menjamin pengiriman segera saat rilis, produsen dapat mengukur berapa banyak permintaan yang akan ada dan dengan demikian ukuran produksi awal berjalan, dan penjual dapat yakin akan penjualan minimum. Selain itu, tingkat suku bunga pre-order yang tinggi dapat digunakan untuk meningkatkan penjualan lebih jauh. ${ }^{25}$

\section{Metode Penelitian}

Penelitian yang dilakukan pada penelitian ini merupakan penelitian deskriptif, yaitu penelitian yang berusaha memberikan gambaran secara sistematis dan cermat fakta-fakta aktual dan sifatsifat populasi tertentu. ${ }^{26}$ kemudian jika ditinjau dari pemakaiannya penelitian ini adalah penelitian lapangan (field reaserch) dengan menggunakan pendekatan metode kualitatif. Metode kualitatif ini

\footnotetext{
${ }^{24}$ Wikipedia dalam www.wikipedia.org diakses 15 Juli 2018

${ }^{25}$ Wikipedia

dalam

www.wikipedia.org diakses 15 Juli 2018

${ }^{26}$ Nurul Zuriah, Metodologi Penelitian

Sosial dan Pendidikan Teori-Aplikasi,(Jakarta:

PT Bumi Aksara, 2009) 14.
}

terdiri dari pengamatan (observasi), wawancara dan penelaahan dokumen. ${ }^{27}$ Penggunaan metode ini dikarenakan metode kualitatif adalah motede yang sesuai dengan kebutuhan dan paling tepat digunakan dalam penelitian ini.

Dalam penelitian ini penulis menggunakan dua sumber data, yaitu :

a. Sumber data primer, yaitu data yang langsung dikumpulkan oleh peneliti dari sumber pertama, adapun yang menjadi sumber data primer ini adalah owner Tiw's.id sebagai pelaku bisnis online shop yang menerapkan sistem jual beli dengan akad pre order (salam).

b. Sumber data sekunder, yaitu data yang sudah siap atau dipublikasikan oleh pihak/instansi terkait dan langsung dapat dimanfaatkan oleh peniliti. ${ }^{28}$

\section{Analisis Praktek Khiyar Pada Jual Beli Pre Order}

Fenomena berbisnis online ini tidak sedikit menimbulkan kritik atau keluhan atas ketidakpuasan customer, baik pada akad pre order maupun ready stok. Pada akad pre order seperti yang sudah disebutkan diatas bahwa barang yang ditawarkan ialah barang contoh yang kemudian dijual dengan cara pemesanan dahulu kemudian proses pembuatan sesuai keriteria yang disebutkan. Dalam online shop bukan

\footnotetext{
${ }^{27}$ Lexy J. Moleong, Metodologi Penelitian Kualitatif,(Bandung: PT Remaja Rosdakarya, 2010) 9

28Ibid, Metodologi Penelitian... 76-77.
} 
hanya dalam akad pre order tapi juga dalam akad lainnya, kekurangan bisnis online ini ialah barang yang ditampilkan merupakan sebuah display atau gambar contoh yang kemudian terkadang menimbulkan perbedaan perspektif atau ekspektasi yang berbeda-beda pada pembeli sehingga kemudian menimbulkan kekecewaan saat barang diterima, namun hal ini merupakan sebuah resiko dari transaksi pada jual beli online, dimana pembeli maupun penjual seakan maklum atau sudah menjadi fenomena yang lumrah akan hal ini, padahal dalam Islam kesempurnaan sebuah transaki atau akad ditandai akan kerelaan diantara penjual maupun pembeli yang berakad. Oleh karena itu dalam transaksi pre order dalam online shop selain menampilkan barang contoh sebagai display untuk ditawarkan kepada pembeli, penjual pun menyebutkan mengenai spesifikasi produk tersebut berupa material (bahan kain) yang digunakan serta ukuran yang dijelaskan secara spesifik, yang kemudian spesifikasinya dapat diminta lebih detail oleh pembeli kepada penjual untuk menghindari terjadinya perbedaan antara barang yang dipesan dan diterima.

Pada Tiw's beberapa konsumen melakukan keluhan dan kritik berupa keluhan terhadap produk yang terdapat cacat, lamanya waktu pengiriman, ataupun ketidakpuasan. Maka dalam hal ini Tiw's menawarkan pilihan berupa (1) pengembalian barang dan pengembalian uang $100 \%$ beserta penanggungan ongkos kirim dengan catatan apabila barang yang diterima terdapat kecacatan. (2) penukaran barang dengan produk lain dan ongkos kirim ditanggung oleh pihak pembeli dengan catatan hanya menukar barang karena kesalahan size atau lain-lain. ${ }^{29}$

\section{Konsep Khiyar Pada Jual Beli Pre Order Online Shop dalam Perspektif Hukum Islam}

Pada dasarnya jual beli baik secara langsung maupun online bersifat sama, hanya saja jual beli online lebih kompleks terhadap kesalahan karena keterbatasan internet, maka dalam hukum Islam praktek jual beli online perlu ditinjau mengikuti dinamisnya perkembangan sistem transaksi bisnis saat ini, karena hukum Islam memiliki aturan yang jelas terhadap masalah-masalah muamalah, walaupun juga memiliki sifat yang fleksibel dalam penerapan prinsipprinsip dasarnya.

Khiyar sebagai hak memilih yang diberikan kepada kedua belah pihak yang berakad (penjual dan pembeli) merupakan hak yang diberikan oleh Islam sebagai salah satu bukti sempurnya Islam mengatur sebuah transaksi, bahwa diluar rukun dan syarat akad jual beli, Islam pun memberikan sebuah hak sebelum melanjutkan akad agar kedua belah pihak merasa saling ridha akan akad yang telah dijalankannya, sebagaimana dalam Al Quran Allah SWT berfirman.

29 Data diambil saat wawancara dengan Istianah, S.E, lihat detail dalam transkip wawancara 
Iqtishoduna: Vol. 8 No. 2 Oktober 2019 | 257

TERAKREDITASI No. 21/E/KPT/2018

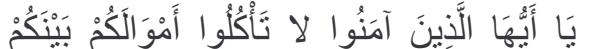

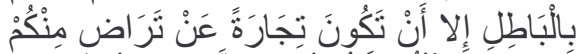

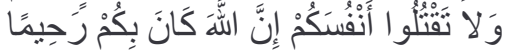

"Wahai orang-orang yang beriman! Janganlah kamu saling memakan harta sesamamu dengan jalan yang batil (tidak benar), kecuali dengan jalan perdagangan yang berlaku atas dasar suka sama-suka di antara kamu. Dan janganlah kamu membunuh dirimu. Sesungguhnya Allah Maha Penyayang kepadamu."

Pada jual beli online shop akad pre order seperti yang telah diidentifikasi, bahwasannya dalam online shop bersamaan dengan proses diterimanya barang yang telah dipesan, maka customer akan memberikan sebuah komentar yang merupakan sebuah kepuasan customer terhadap barang yang telah dipesan atau erringg disebut testimoni, dengan testimoni tersebut maka dapat ditinjau oleh owner online shop mengenai kepuasan maupun kritik customer, Kemudian bila ada suatu kecatatan barang atau ketidakpuasan customer terhadap barang yang dipesan seperti yang telah disebutkan diatas, owner Tiw's sebagai penjual online shop menawarkan opsi berupa pengembalian barang kepada pihak online shop dan pengembalian uang kepada pihak pembeli atau opsi berupa pengembalian barang dengan barang baru.

$$
\text { Online shop Tiw's }
$$

memberikan hak khiyar secara tidak langsung berupa, pertama (1) khiyar majlis pada saat customer memberikan testimoni saat barang diterima, sebagaimana sabda Rasulullah SAW

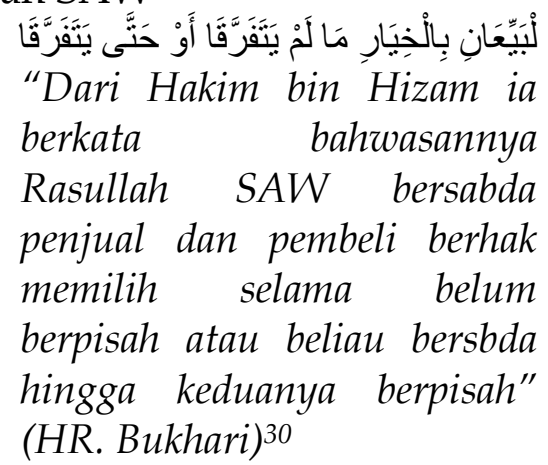

Lama waktu selama berlangsungnya transaksi pre order dalam online shop dapat diartikan sebagai dua orang yang berakad yang masih dalam satu majlis transaksi karena keduanya belum berpisah karena keduanya masih terikat akad dari awal pemesanan, pengerjaan barang pesanan sampai kemudian barang diterima.

Kedua (2) khiyar aib yang berlangsung dalam online shop Tiw's dapat dilihat saat customer menerima barang pesananya, saat terdapat cacat atau aib maka khiyar aib pun berlangsung, dimana customer diberikan hak untuk memilih dan melihat brarang pesanannya kemudian bila menemukan sebuah kecatatan maka owner Tiw's memberikan gantinya, maka ini sesuai seperti sabda Rasulullah SAW من انترى شيئا لم يراه فهو بالخيار اذاراه”
"siapa yang membeli sesuatu
yang belum ia lihat, maka ia
berhak khiyar apabila telah

${ }^{30}$ Muhammad ibn ismail ibn Ibrahim ibn al mughirah al bukhary abu abdillah, al jami' as shahih al mukhtasar min umuuri Rasulillah SAW wa sunanihi wa ayyamiih, hadits no.2109 (Daar turuq an najah, 1422H) 
258 Dafiqa Hasanah, dkk: Konsep Khiyar Pada Jual Beli Pre Order Online...

melihat barang itu" (HR. adDharqutni dan Abu Hurairah) ${ }^{31}$

Aib atau kecatatan barang dapat berupa sebuah kesalahan owner online shop dalam proses sortir barang (terlewat saat mensortir barang yang cacat), namun juga dapat berupa kekurangpuasan customer pada barang yang diterima (seperti kesalahan size atau warna barang) yang kemudian membuat owner online shop Tiw's memberikan sebuah hak khiyar, yaitu berupa khiyar aib atas barang produksinya.

Kesempurnaan Islam dalan mengatur sebuah transaksi jual beli selain memberikan aturan yang jelas mengenai rukun dan syarat jual beli yang telah disyariatkan tapi juga Islam mengedepankan asas saling ridha agar tercipta jual beli yang diridhai Allah SWT, sebagaimana dalam hadist qudsi bahwa Allah SWT menyamakan antara syurganya penjual yang jujur dengan para Nabi.

\section{Kesimpulan}

Praktek jual beli akad pre order pada online shop sama halnya dengan jual beli akad salam hanya saja dilakukan tanpa face to face tapi menggunakan internet. Jual belipre order dalam online shop menampilkan barang berupa display dan deskripsi barang tersebut kepada customer kemudian customer memesan dengan rincian ukuran dan warna dari barang yang diinginkan kemudian barang

31 Muhammad Dhiya ar rahman al a'dzhamy, Al minnah al kubra syarh wa takhrij as sunan al shugra, hadits no. 1835 (Riyadh: maktabah ar rusyd 2001M) pesanan akan dikerjakan dengan perjanjian lama waktu pengerjaan yang telah disepakati kemudian setelah barang jadi maka barang akan dikirim kepada customer dengan jasa ekspedisi hingga diterimanya barang ditangan customer, kemudian khiyar dalam jual beli pre order online shop terjadi secara tidak langsung ketika customer memberikan testimonial kepada owner online shop berupa kepuasan customer, kekecewaan ataupun complain atas barang yang diterima dapat dikategorikan sebagai khiyar majlis karena pembeli dan penjual masih dalam satu ikatan transaksi. Setelah itu, testimonial tersebut akan direspon oleh owner, yang apabila terdapat kekecewaan maka owner akan memberikan respon berupa sebuah penawaran return atau pengembalian barang atau uanh bilamana barang yang diterima rusak atau terdapat caca, dalam hal ini khiyar aib berlangsung. Oleh karena itu meskipun jual beli online dihalangi oleh keterbatasan internet tetapi tidak justru membuat nilai nilai transaksi dalam Islam yang dianjurkan menjadi hilang, seperti praktek khiyar dalam transaksi pre order online shop ini yang terjadi secara tidak langsung.

\section{Saran}

Praktek jual beli pre order online shop bukanlah menjadi sesuatu yang baru dikalangan masyarakat saat ini sehingga masyarakat faham mengenai prosedur jual beli ini sehingga owner 
Iqtishoduna: Vol. 8 No. 2 Oktober 2019 | 259

TERAKREDITASI No. 21/E/KPT/2018

atau sebagai penjual maupun pembeli hendaknya menunaikan masing-masing hak jual beli agar menghindari terjadinya transaksi yang tidak dilandasi oleh prinsip suka sama suka sehingga tidak meunculnya keridhaan akan dua orang yang berakad.

\section{Daftar Pustaka}

Ayu Lestari,Bisnis online syariah, kompas gramedia, Jakarta 2014

Mas'adi A Gufron,fiqih muamalah kontekstual, Jakarta, PT raja grafindo persada 2002

Moeleong J lexy, Metodologi Penelitian Kualitatif, Bandung, PT remaja rosdakarya 2012

Badri bin arifin Muhammad, Sifat Perniagaan Nabi, Bogor CV darul ilmi 2008

Faturrahman jamil, Hukum Ekonomi Islam, Jakarta, sinar grafika 2013

Jusmaliani, Bisnis Berbasis Syariah, Jakarta, bumi aksara 2008

Muhammad tahir mansori, Kaidah Kaidah Fiqih Keuangan dan Transaksi Bisnis, Bogor ulil albab institute 2010

Syaikh ziyad ghazal, Buku Pintar Bisnis Syar'i, al azhar press, bogor 2011

Nasrun haroen, Fiqih Muamalah, gaya media pratama, Jakarta 2007
Muhammad arifin badri, Tuntunan Syariah untuk Meraih Bisnis dan Rezeki Barokah, majalah pengusaha muslim, jogyakarta 2013

Ahmad shabiq, Gharar dalam transaksi komersial, Majalah Al-Furqon No. 145 Ed. 9 Th ke-13, 2014

Shalih bin Fauzan Al-Fauzan, Jual Beli yang Dilarang dalam Islam, Kendari: Maktabah Raudhatul muhibbin, 2008

Sayyid Sabiq, Fikih Sunnah, Bandung Darul Ma'arif,1996

Wahbah Zuhaily, Al-Figh al-Islâm wa 'Adilatuhûu Jilid IV Beirut Dâr Al-Fikr, 1984

Ibdalsyah dan hendri tanjung, Fiqih muamalah, bogor 2014

hendri tanjung dan abrista devi, Metodologi penelitian ekonomi islam, gramata publishing, bekasi 2013

Ahmad Wardi Muslich, Figh Muamalat, Jakarta:Amzah

Ahmad shabiq, Gharar dalam Transaksi Komersial, Majalah AlFurqon No. 145 Ed. 9 Th ke-13, 2014

Ibdalsyah dan hendri tanjung, Fiqih muamalah, bogor 2014

hendri tanjung dan abrista devi, Metodologi Penelitian Ekonomi Islam, gramata publishing, bekasi 2013 
260 | Dafiqa Hasanah, dkk: Konsep Khiyar Pada Jual Beli Pre Order

Nurul Zuriah, Metodologi Penelitian Sosial dan Pendidikan TeoriAplikasi, Jakarta: PT Bumi Aksara, 2009

Software Hadits Al - Maktabah Syamilah 